\title{
A theory of progression from obstructed defecation to fecal incontinence
}

\author{
F. Pucciani ${ }^{1}$
}

Received: 16 October 2015/Accepted: 16 October 2015/Published online: 14 November 2015

(C) Springer-Verlag Italia Srl 2015

Fecal disorders have a relevant social impact because they impair the quality of life of the patient and add to the cost of healthcare. In order to shed light on the pathophysiology of fecal disorders it is helpful to consider the progression of obstructed defecation to fecal incontinence which occurs in women without anal sphincter defects who have descending perineum syndrome.

The overall prevalence of chronic constipation in the general population is about $15 \%$, and the most common subtype among women is obstructed defecation. Obstructed defecation occurs in $47.7 \%$ of Italian patients affected by chronic constipation. Dyssynergia alone is present in young women (median age $38 \pm 14$ years), whereas dyssynergia plus structural diseases, such as rectocele, rectal intussusception, mucosal prolapse and perineal descent materialize in middle-aged women (median age $52 \pm 14$ years) [1]. Therefore there is no doubt that ageing is implicated in the evolution from functional to anatomic pelvic floor disorders. In parallel, excessive abdominal straining at stool evacuation causes progressive perineal descent: the recurrent straining against defecatory outlet obstruction impairs pelvic floor muscle tone until it disappears completely. In this way descending perineum overlaps with pelvic floor dyssynergia [2]. Older age is correlated with both dynamic and fixed descending perineum [3], and excessive perineal descent is found in $78 \%$ of elderly patients with evacuation disorders [4]. The organic descent of the hypotonic pelvic floor combined

F. Pucciani

pucciani@unifi.it

1 Department of Surgery and Translational Medicine, University of Florence, Largo Brambilla 3, 50134 Florence, Italy with pudendal neuropathy explains the appearance of fecal incontinence. Perineal descent involves the anterior, middle and posterior pelviperineal areas in women. Uro-gynecological structures and proctologic segments are all implicated and thus pelvic organ prolapse may coexist with rectoanal intussusception, rectal prolapse and rectocele [5].

Fecal incontinence is a physically and psychologically disabling condition which has a negative impact on the quality of life of the patient. The prevalence of fecal incontinence in community-dwelling women in the USA varies considerably depending on the population studied, ranging from 2.2 to $17 \%$ of women housed in communities and up to almost half of all nursing home residents. Fecal incontinence is often related to several specific diseases, such as diabetes mellitus, dementia, irritable bowel syndrome, cerebrovascular disease, pelvic-anal surgery, traumatic sphincter lesions and post-partum incontinence. Even when excluding the presence of these cases, women over 65 years often have combined chronic constipation and fecal incontinence (32.7\% of constipated women) and women with anal incontinence have greater values of descending perineum measures than those without anal incontinence [6]. Therefore, these last epidemiological data support the hypothesis of a link between obstructed and fecal incontinence via descending perineum syndrome.

Obstructed defecation can be caused by organic or functional diseases which are difficult to untangle. Mechanical causes include rectocele, rectoanal intussusception, descending perineum syndrome, solitary rectal ulcer syndrome, mucosal rectal prolapse, enterocele and sigmoidocele. Disorders of rectal sensation and pelvic floor dyssynergia are the functional diseases. Patients with rectal hyposensitivity have most commonly constipation (48 \%), combined constipation and incontinence $(27 \%)$, or fecal incontinence $(20 \%)$. Obstructed defecation patients have a 
significantly higher rectal sensitivity threshold than controls. The relationship between rectal hyposensitivity and pelvic floor dyssynergia suggests a causative relation of the two, possibly from blunting of the urge to defecate in patients with rectal hyposensitivity [7]. This first complex mechanism is amplified and maintained as the beginning of descending perineum: excessive abdominal straining at stool evacuation, induced by pelvic floor dyssynergia and rectal hyposensitivity as stated above, has been identified as the cause of progressive perineal descent with relevant negative influence on the pelvic fascia and pelvic muscles. The decline in normal levator ani tone, induced by overstretching, results in an open urogenital hiatus, weakening of the horizontal orientation of the levator plate, and a bowllike configuration [8]. When obstructed defecation occurs, regardless of the cause, whether functional or mechanical, a small amount of stool is retained in the rectum at the end of defecation and is not perceived due to impaired rectal sensation [9]. Subsequently this small amount of stool may leak out of the anus and soil the underwear during a sampling reflex because of impairment of conscious contraction of the anal sphincter, resulting in unconscious leakage.

The clinical patterns of fecal incontinence may be defined according to Engel's criteria and is classified as urge incontinence, passive incontinence, mixed incontinence and post-defecatory incontinence. Each profile is specific and is related to specific sphincter abnormalities, but the impairment of sensation and the motility of the rectum may play a role. In urge incontinence anorectal manometry reveals a significantly lower maximum voluntary contraction pressure, low maximal tolerated volume and impaired rectal compliance. Passive incontinence is fecal incontinence that the patient is not aware of. Anorectal manometry reveals low resting anal pressure and/or rectal hyposensitivity with high rectal sensations. A low resting anal pressure is related to impaired function of the internal anal sphincter that may be secondary to traumatic lesions and/or atrophy. This manometric sign can be found during evaluation of some patients with obstructed defecation indicating that their internal anal sphincter is probably impaired. Rectal hyposensitivity is also present in obstructed defecation, and if the rectal sensation volume is higher than the rectoanal inhibitory reflex threshold volume, passive fecal leakage may occur in the absence of cortical recognition of the defecatory event. Therefore we can say that every pattern of fecal incontinence can overlap with obstructed defecation. In defecographic images of women with descending perineum, rectocele and rectoanal intussusception may be detected, as well as a poor anorectal angle opening at evacuation. This supports the hypothesis that pelvic floor dyssynergia may be a patho-

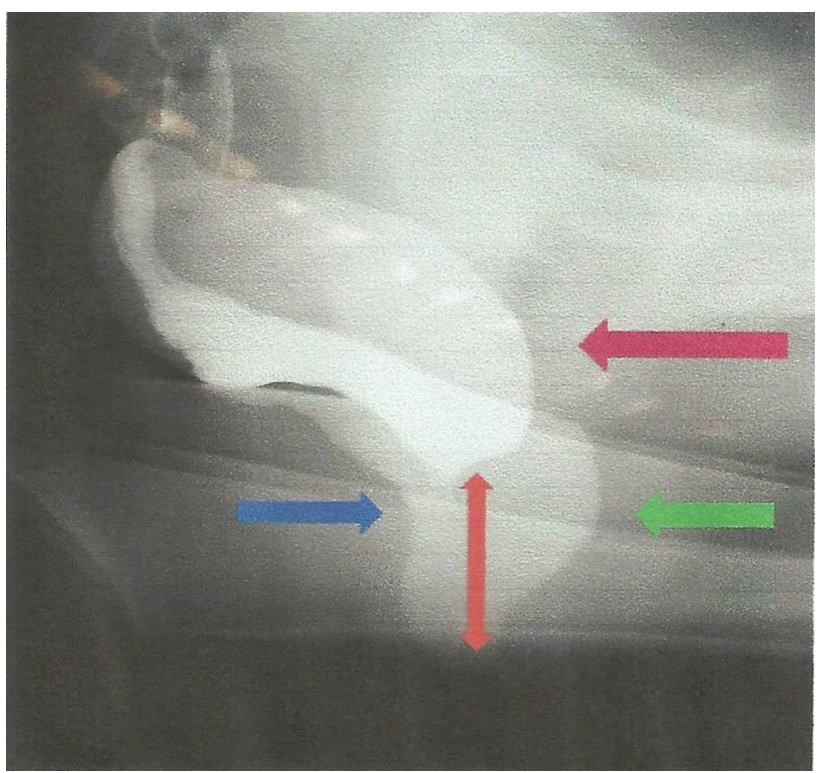

Fig. 1 Defecography. Pelvic floor dyssynergia and descending perineum. Double exposure technique with evacuative image (green arrow) superimposed on an image at rest (red arrow). Note the descent of the perineum $(4.3 \mathrm{~cm}$-vertical orange arrow $)$ and persistence of puborectalis indentation (blue arrow) in the evacuative image

physiological factor for mobile descending perineum syndrome (Fig. 1).

Up to now, the exact pathway leading from obstructed defecation to fecal incontinence has not been clearly defined because the follow-up of patients would be have to be very long, lasting several decades, in order to show the complete progression to fecal incontinence. However, it seems logical that many years of obstructed defecation may impair a patient's pelvic floor structure. The pathway to fecal incontinence can be predicted and inevitably will materialize with the passage of time, due to the hypotonia of pelvic floor and associated pudendal neuropathy. It is obvious that many factors may influence the progression to fecal incontinence such as childbirth, pelvic surgery, rectoanal surgery, anal sphincter lesions, radiotherapy and neurologic diseases, which all can have negative impact on continence.

\section{Compliance with ethical standards}

Conflict of interest The author declares that they have no conflict of interest.

Ethical approval This article does not contain any studies with human participants or animals performed by any of the authors.

Informed consent Informed consent was not required for this type of study. 


\section{References}

1. De Nuntis S, Bevilacqua M, Forlini G, Rossi Z (1998) Pelvic floor dyssynergia: videoproctographic analysis and pathologic associations in defecation obstruction syndrome. Radiol Med 96:73-80

2. Pucciani F (2015) Descending perineum syndrome: new perspectives. Tech Coloproctol 19:443-448

3. Chang J, Chung SS (2012) An analysis of factors associated with increased perineal descent in women. J Korean Soc Coloproctol 28:195-200

4. Harewood GC, Coulie B, Camilleri M, Rath-Harvey D, Pemberton JH (1999) Descending perineum syndrome: audit of clinical and laboratory features and outcome of pelvic floor retraining. Am J Gastroenterol 94:126-130

5. Maglinte DD, Kelvin FM, Fitzgerald K, Hale DS, Benson JT (1999) Association of compartment defects in pelvic floor dysfunction. AJR Am J Roentgenol 172:439-444
6. Kahn MA, Breitkopf CR, Valley MT et al (2005) Pelvic Organ Support Study (POSST) and bowel symptoms: straining at stool is associated with perineal and anterior vaginal descent in a general gynecologic population. Am J Obstet Gynecol 192:1516-1522

7. Gladman MA, Lunniss PJ, Scott SM, Swash M (2006) Rectal hyposensitivity. Am J Gastroenterol 101:1140-1151

8. Singh K, Jakab M, Reid WM, Berger LA, Hoyte L (2003) Threedimensional magnetic resonance imaging assessment of levator ani morphologic features in different grades of prolapse. Am J Obstet Gynecol 188:910-915

9. Pucciani F (2013) Faecal soiling: pathophysiology of postdefecatory incontinence. Colorectal Dis 15:987-992 